\title{
Health Canada's Wind Turbine Noise and Health Study - A Review Exploring Research Challenges, Methods, Limitations and Uncertainties of Some of the Findings
}

\author{
Carmen M. Krogh1,2*, Anne Dumbrille3, Robert Y. McMurtry ${ }^{4,5,6}$, Richard James ${ }^{7,8,9}$, \\ Robert W. Rand10,11, Michael A. Nissenbaum12,13,14, Jeffery J. Aramini15, \\ Stephen E. Ambrose ${ }^{16,17,18}$
}

${ }^{1}$ The Society for Wind Vigilance, Member of the Board of Directors, Canada

${ }^{2}$ Magentica Research Group, Member of the Board of Directors, Canada

${ }^{3}$ CCSAGE Naturally Green (County Coalition for Safe and Appropriate Green Energy), Picton, Ontario, Canada

${ }^{4}$ Emeritus Schulich School of Medicine and Dentistry, Western University, London, Ontario, Canada

${ }^{5}$ Former Dean Medicine and Dentistry, Western University, London, Ontario, Canada

${ }^{6}$ Visiting Specialist, Prince Edward County Family Health Team, Picton, Ontario, Canada

${ }^{7}$ Acoustical Society of America (ASA), Canada

${ }^{8}$ Institute of Noise Control Engineering (INCE) through 2007, Canada

${ }^{9}$ The Society for Wind Vigilance, Canada

${ }^{10}$ Institute of Noise Control Engineering (INCE-USA Member Emeritus as of 1/1/2019), Brunswick, ME USA

${ }^{11}$ Acoustical Society of America (ASA), Brunswick, ME USA

${ }^{12}$ RADIMED, Canada

${ }^{13}$ McGill University, Montreal, Canada

${ }^{14}$ The Society for Wind Vigilance, Member of the Board of Directors, Canada

${ }^{15}$ Fergus, Ontario, Canada

${ }^{16}$ Institute of Noise Control Engineering (INCE), Windham, Maine, USA

${ }^{17}$ Acoustical Society of America (ASA), Acoustics, Environmental Sound and Industrial Noise, Windham, Maine, USA

${ }^{18} \mathrm{SE}$ Ambrose \& Associates, Windham, Maine, USA

Email: *carmen.krogh@gmail.com

How to cite this paper: Krogh, C.M., Dumbrille, A., McMurtry, R.Y., James, R., Rand, R.W., Nissenbaum, M.A., Aramini, J.J. and Ambrose, S.E. (2018) Health Canada's Wind Turbine Noise and Health Study-A Review Exploring Research Challenges, Methods, Limitations and Uncertainties of Some of the Findings. Open Access Library Journal, 5: e5046.

https://doi.org/10.4236/oalib.1105046

\begin{abstract}
Background: Risk of harm associated with wind turbines is debated globally. Some people living or working in proximity to wind turbines report adverse health effects such as sleep disturbance, noise annoyance, and diminished quality of life. Due to public concern, Health Canada announced its wind turbine noise and health study which included subjective and objective measurements. Findings were published between 2014 and 2016. In 2018, Health Canada published clarifications regarding the design and interpretation of study conclusions. Methods: Methods and subjective/objective findings were
\end{abstract}


Received: November 13, 2018

Accepted: December 17, 2018

Published: December 20, 2018

Copyright (c) 2018 by authors and Open Access Library Inc.

This work is licensed under the Creative Commons Attribution International License (CC BY 4.0).

http://creativecommons.org/licenses/by/4.0/ reviewed. Peer reviewed publications, conference presentations, judicial proceedings, government documents, and other sources were evaluated and considered in context with advanced methods for investigating reports of adverse health effects. Objectives: To review and explore some of the research challenges, methods, strengths and limitations of findings and conclusions. To participate in scientific dialogue and contribute towards an understanding of reported health risks associated with wind turbine noise. Results: Wind turbine human health research is challenged by numerous variables. Knowledge gaps and individual human and wind turbine variables are identified. Strengths and advisories of limitations are considered and acknowledged. Health Canada's advisories that its study design does not permit any conclusions about causality and results may not be generalized beyond the sample taken in Canada are supported. Enhanced methods for investigating health outcomes are proposed including establishing referral resources within medical facilities for physicians. It is proposed staffing of the resource center includes multidisciplinary teams of physicians, epidemiologists, acousticians and other specialists to investigate suspected wind turbine adverse health effects. Discussion: A review and the appraisal of some of the research challenges associated with wind turbine human health research are presented. Given the identified methods, research/knowledge gaps, and limitations and cautionary advisories, Health Canada's results should be carefully considered when predicting or protecting from health risks of wind turbine noise.

\section{Subject Areas}

Public Health

\section{Keywords}

Wind Turbines, Research Challenges, Research Gaps, Risk of Harm, Adverse Health Effects

\section{Introduction}

The risk of harm to humans associated with exposure to wind energy facilities is controversial and debated globally [1] [2] [3] [4]. Industrial wind turbine (WT) health research is challenged by a number of variables such as: WT noise and power output; proximity and sitting array; terrain; and seasonal and atmospheric conditions. Additional research challenges are more likely to occur when the WT variables are combined with human variables such as individual response to noise; social and economic issues; risks to vulnerable population groups associated with age (fetus, children and elderly) including those with special needs and who have pre-existing medical conditions.

Some people exposed to WT report adverse health effects such as sensations, sleep disturbance, noise annoyance, cognitive disorders, lowered general health and reduced quality of life [3] [5]-[10]. In some cases, Canadian and other fami- 
lies residing in proximity to WT have effectively vacated their homes [11] [12], been billeted by WT project developers [13] or successfully negotiated financial agreements [11].

There are limited studies related to occupational workers. A scoping review by Freiberg et al. 2018 found "no specific overall health effects of working in the wind sector" but found associations with accident rates which resulted in injuries or fatalities [5]. Other occupational worker research has reported WT noise annoyance and other adverse health effects which are consistent with reports by residents who live near WT [14]-[20].

Audible and inaudible noise, noise annoyance, visual impacts, stray voltage, and social impacts have been identified as potential/plausible causes of adverse health effects [3] [8] [11] [12] [15] [21].

Health Canada observed there is "public concern for potential health impacts, which include disrupted sleep from exposure to wind turbine sound" [22]. In 2012, the design of Health Canada's Wind Turbine Noise and Health Study (Health Canada Study) was announced and the public advised the approach will:

... support decision makers by strengthening the evidence base of peer reviewed scientific research that ultimately supports decisions, advice and policies regarding wind power development proposals, installations and operations in Canada [23].

While the Health Canada Study is known as the "Wind Turbine Noise and Health study", it is also referred to as the CNHS (Community Noise and Health Study [24]. During 2013, in collaboration with Statistics Canada [25], Health Canada conducted its cross-sectional study and published results during 2014, 2015 and 2016 [24]-[32]. Subsequently in response to comments expressed by some, Health Canada clarified the Health Canada Study design and interpretation of conclusions [33].

For the interest of readers, publications by Michaud et al. 2016 [24] [28] [30] have provided corrections related to the following Health Canada Study results [34] [35] [36]. Corrections include regarding reference [28], an advisory that the data file used to analyse the objective sleep endpoints included data processing errors and the steps taken to conduct a reanalysis [34]; for reference [24] correction of a citation and an endnote description [35]; and for reference [30] corrections of a citation, plus advisories to reduce the values in one of the figures and to shift a WT noise curve by approximately $0.8 \mathrm{~dB}$ [36].

Health Canada conducted pilot interviews to test the questionnaire and participants' overall comprehensiveness and willingness to participate in both subjective and objective measurements. Results obtained from the pilot were not included in the published findings [22]. Data were collected between May and September 2013 [24]. The study design included self-reported and objectively measured health indicators such as blood pressure and heart rate, hair cortisol (as a biomarker of stress), sleep actigraphy data to assess sleep quality and a computer assisted face-to-face personal interview administered in the participant's home [22]. 
In 2013 and 2014 Health Canada cautioned that regarding the Health Canada Study design:

- results will not provide a definitive answer on their own [37];

And that:

- results may not be generalized to areas beyond the sample as the wind turbine locations in this study were not randomly selected from all possible sites operating in Canada;

- results do not permit any conclusions about causality; and,

- results should be considered in the context of all published peer-reviewed literature on the subject [25].

The Health Canada Study findings have been referenced in support of various procedures such as: an Ontario Ministry of Environment and Climate Change regulatory framework [38] and during various legal and other proceedings [39]-[46].

Indications are in some cases, the Health Canada Study findings appear to have been interpreted beyond Health Canada's advisories of the above limitations and/or failed to differentiate these.

This article considers WT related research challenges and knowledge gaps. In addition, it reviews Health Canada's subjective/objective methodologies and explores some of the limitations and uncertainties related to published findings and conclusions. Approaches for augmenting methods are proposed with the goal of participating in scientific dialogue and contributing towards future investigations of WT and human health.

\section{Method}

The Health Canada Study methods were reviewed and assessed. Some of the research challenges associated with this topic were explored and a number of factors and methods which could influence research findings identified. These include methods such as: use of WT calculated noise models; sampling and analytical methods of hair cortisol; consideration of acute verses chronic exposure; and outcomes of objective and subjective measurements. Research and knowledge gaps were considered and evolving research methods identified. Enhanced WT methods for investigating health outcomes associated with living or working in proximity to WT are proposed.

Reference sources include:

- peer reviewed publications and conference papers associated with WT acoustical noise research, adverse health effects, research challenges and knowledge gaps;

- expert testimony during judicial and other proceedings;

- rulings of judicial proceedings;

- authoritative documents such as those from government and other jurisdictions; and

- other sources. 


\section{Results}

\subsection{Calculated Wind Turbine Noise Models}

It is common practice to rely on calculated WT noise models. The Health Canada Study followed this approach for both A- and C-weighed noise [47] [48]. There is evidence that divergence between WT calculated and actual full spectrum noise measurements could influence findings. For example, Barlas et al. indicate that to the authors' knowledge "none of the noise mapping tools take into account the increased source levels due to ambient or wake induced turbulence. Neither the standards demand turbulence dependent noise curves" which can be one of the reasons for "inaccurate far field noise predictions" [49].

A study by Iannace observed that "People complain about a greater noise due to particular wind speed conditions" and that depending on placement of WT and wind direction "the contribution to the sound level due to wind speed increase is considerable, which is about $10 \mathrm{~dB}$ " [50]. In a systematic review, Schmidt and Klokker suggested "It might be relevant to include another type of sound weighting rather than just the A-weighting in future studies" [51].

Determining WT compliance has methodological issues as well. For example, the use of calculated models which typically predict A-weighed noise levels outside a home do not necessarily correspond to the actual noise level inside a home environment during the time an adverse effect occurred. A study by Gortsas et al. 2017 comments:

The most important conclusions here are 1) the microseismicity creates higher levels of noise inside a house than that of the airborne noise radiated by a WT and 2) bedrock being in low depths underneath the soil has an additional contribution to the generated acoustic noise by the induced microseismicity [52].

The Administrative Appeals Tribunal (AAT), appointed by the Attorney General of Australia, provides an independent review of decisions made by the Australian Government. A judicial Decision accepted that regarding the Health Canada Study "measurements based on estimates or averages may not accurately reflect the sound which was present when the particular level of annoyance was experienced or recorded" [53] and that:

A major limitation is that the conclusions of the study were based on calculated, rather than actual, noise measurements (although some of the calculated noise levels were based on measurements). [[53] pg 146] [para. 478] All of the evidence before us is to the effect that WTN cannot be accurately captured in $\mathrm{dB}(\mathrm{A})$, or even $\mathrm{dB}(\mathrm{C})$ (although $\mathrm{dB}(\mathrm{C})$ is preferable) [[53] pg 146] [para. 479].

The lack of actual noise measurements could have influenced the analysis of self-reported findings obtained during the computer assisted face-to-face personal interview and the objectively measured health indicators such as stress, 
blood pressure and heart rate. Full spectrum noise measurements sensitive to the fluctuations in amplitude from dynamic pressure pulses, including infra and low frequency sound could have enhanced the overall study design. In addition, the application of actual noise measurements combined with technology such as remote monitoring or the SCADA (Supervisory Control and Data Acquisition) [54] for real time supervisory control and monitoring of each WT to determine the operational status of the WT during the correlation and interpretation of the objective and subjective measurements could have contributed towards an understanding of the health outcomes.

Subsequent to the publication of the Health Canada results related to sleep [28], attendees of a WT noise conference session were advised that a more refined analysis was being conducted "to assess wrist actigraphy measured sleep patterns in relation to nightly variations in wind turbine operations" [55]. Health Canada's slide presentation disclosed WT sound power level was calculated using SCADA for the 3 nearest WT. The recalculation was restricted to a subset: i.e., 275 (116 males, 159 females) living between 0.25 and $1 \mathrm{~km}$ from wind turbines [56] resulting in $35.2 \%$ of the 781 participants' data being reassessed.

Michaud et al. [28] concluded that the study results do not "support an association between exposure to outdoor WTN up to $46 \mathrm{~dB}(\mathrm{~A})$ and an increase in the prevalence of disturbed sleep". These conclusions are based on WT noise averaged over one year. Michaud et al. [28] also suggested that in some cases, results may be "strengthened with an analysis that examines sleep quality in relation to WTN levels calculated during the precise sleep period time". While the reanalysis indicated there is "no impact on any of the self-reported outcomes and the overall conclusion of the original paper does not change." [33 of reference 28], consideration of sleep quality and precise sleep time could potentially clarify potential WT related sleep issues.

Except for the above subset of participants, it appears the operational status of the WT was unknown i.e., whether the WT were turned off or on, operating at partial or full capacity or ramping up or down during the interviews and the measurements of heart rate and blood pressure.

While several studies have conducted actual noise measurements during the times the WT were turned off and on [7] [50], cooperation of the WT developer would support a full spectrum actual noise measurement methodology including the WT operational status. This would give the ability to compare actual noise measurements with calculated/predictive noise models.

It is recommended that during the investigation of reported adverse health effects, actual full spectrum noise measurements be taken inside and outside a sample of family homes and interpretation of subjective and objective measurements be correlated with WT operational status, i.e., turned off, operating at partial or full capacity or ramping up or down. Actual full spectrum noise measurements should be evaluated and compared to calculated noise models when 
considering human health findings.

\subsection{Cortisol and Low Frequency Noise (LFN)}

Although there is convincing evidence in the literature that cortisol levels can be an indicator of exposure to stress, variables such as inaudible infra and low frequency noise (LFN) may have the potential to influence results. While the Health Canada Study relied on calculated noise models for both A- and C-weighed noise [47] [48], actual field noise measurements indicate the occurrence of LFN/infrasound [52] [57] [58]. Four firms which cooperatively conducted actual WT noise measurements commented they were of "the opinion that enough evidence and hypotheses have been given herein to classify LFN and infrasound as a serious issue, possibly affecting the future of the industry" [59].

Persson Waye et al. [60] examined and compared the effects of LFN and night-time traffic noise on the cortisol awakening response and subjective sleep quality. The data indicated that responses during exposure to the two types of noise differed. The cortisol awakening response was altered following nocturnal exposure to LFN in that cortisol levels had not peaked by thirty minutes after awakening. The attenuated levels of salivary cortisol were related to tiredness and negative mood. This was not the case with exposure to night-time traffic noise or reference nights. While the authors advised to interpret the results with caution it was concluded that the study showed "night time exposure to LFN may affect the cortisol response upon wake up and that lower cortisol levels after awakening were associated with subjective reports of lower sleep quality and mood".

Relying on calculated models risks "inaccurate far field noise predictions" [49] and when combined with the potential for LFN to reduce cortisol levels, these factors could have influenced the results of the objective measurements of hair cortisol.

Rather than relying on calculated LFN/infrasound (C-weighted sound pressure levels), conducting actual noise measurements in a representative sample of participants may have clarified the potential for inaccuracies in the interpretation of study results. It is proposed that these factors be considered and controlled in future WT investigations.

\subsection{Hair Cortisol: Excluded Samples}

Michaud et al. [29] report that of the 917 samples collected during the Health Canada Study, over 26\% (n-242) were excluded or discarded:

- 214-too little hair was taken;

- 9-levels were too high;

- 19-high levels of which 14 used chemical treatment in the last 3 months.

The validity of excluding $28(9+19)$ samples due to high levels which included the use of chemical treatment in the last 3 months is unclear and has not been justified. Research indicates hair cortisol levels are not affected by hair 
color or by dyeing hair samples after they were obtained [61]. The high values may indicate an unidentified problem with the specificity of the assay or that the research subjects were highly stressed.

If chemical treatment were considered an issue, samples from those who had chemically treated their hair during the past 3 months should have also been excluded. This would have ensured consistency of the remaining 675 (917 - 242) individuals. It is unclear whether this was considered.

It is recommended that chemical and color/dyeing treatment be consistently considered during hair cortisol sampling.

\subsection{Hair Cortisol Values}

Michaud et al. 2018 [33] observe that "higher perceived stress scores were related to higher hair cortisol concentrations". The study by Michaud et al. [29], Table I states that hair cortisol values ranged from 18 to $7139 \mathrm{ng} / \mathrm{g}$ (pg/mg) with Table 3 indicating many samples were over $200 \mathrm{ng} / \mathrm{g}$. The stated values are substantially higher than those typically reported in the literature: Sauvé et al. [62] indicate a reference range for hair cortisol of 17.7 - $153.2 \mathrm{pg} / \mathrm{mg}$ of hair (median 46.1 $\mathrm{pg} / \mathrm{mg}$ ) and Karlan et al. [61] report levels of up to $212 \mathrm{pg} / \mathrm{mg}$ (mean levels 17 $20 \mathrm{pg} / \mathrm{mg}$ ) while a study across countries which also compared measurement kits indicate only a 2.3-fold difference [63].

No reason was given for the Health Canada Study values being above those published in the literature. A possible explanation is that cortisol levels were elevated in some patients of all WT noise groups. This could have been due to an exposure other than audible noise such as WT LFN/infrasound as compared to those with no WT exposure. If some subjects were sensitive to inaudible infrasound, effects of WT could potentially extend beyond Health Canada's study area of $10 \mathrm{~km}$. An alternate explanation is sample or assay error. For levels to be so much higher and more variability than other published studies requires some justification.

The advice of the Health Canada SAB (Science Advisory Board) provides some guidance: in 2012 the SAB recommended that Health Canada investigators consider supplementing hair cortisol with a group that provides saliva cortisol for diurnal patterns [64].

In order to support future WT investigations related to stress, it is proposed that consideration be given to the $\mathrm{SAB}$ recommendation.

\subsection{Hair Cortisol Sampling}

Hair cortisol measurements have been used when it is impractical or inconvenient to collect saliva or a 24-hour urine sample or blood.

Based on the approximate rate of hair growth, one centimetre of hair typically indicates the average cortisol level over a month. The Health Canada Study methodology indicates that "subjects from whom a length of $3 \mathrm{~cm}$ or more of hair was collected" was used to measure cortisol values [29]. A $3 \mathrm{~cm}$ sample pro- 
vides cortisol values averaged approximately over a 3 month period. Due to averaging the cortisol values, the results may indicate chronic levels but are less likely to reflect acute situational or individual stresses. Measuring segmented hair over about a 1 month period would provide a more specific indication of stress, but even that would average out dips and spikes in cortisol values, thereby masking acute releases of cortisol.

Based on the Health Canada Study's methodology for measuring hair cortisol, there is no indication segmented hair was assessed.

Another consideration is if some residents were sensitive to noise, and/or infrasound/LFN, and/or WT were exceeding the approved operational range, the data relating to an increase of cortisol would be lost or un-interpretable due to averaging this objective measurement. Since Health Canada Study relied on predictive noise calculations [47] [48], actual noise levels are unknown. Applying measures of cortisol release over short periods of time, such as those collected by salivary or urine, with correlation of subjective/objective measurements to actual noise levels as well as WT operational status could have provided comparative information.

To assist with measuring peak stress, it is recommended that future WT investigations consider including either a study or sampling group and to correlate subjective and objective measurements while conducting full spectrum actual audible and inaudible noise measurements inside and outside family homes as well as capturing WT operational status including hub rpm, wind speed and direction at the hub for each WT within $10 \mathrm{~km}$ of a family home.

\subsection{The Enzyme-Linked Immunosorbent Assay (ELISA) Methodology}

Stress-induced cortisol changes have been measured using blood and saliva or a 24-hour urine sample which can be elusive to interpret. Serum and salivary cortisol levels at a point in time reveal acute changes. However, it is difficult to evaluate chronic systemic cortisol [65], is subject to "variations due to acute stress, the diurnal rhythm and pulsatile secretion" [66] and "challenging due to the need to take multiple urine, saliva or serum samples" [62]. As a result, the use of hair cortisol measurements has been increasingly recognized [65] [66] [67] [68]. Sauvé et al. [62] compared hair cortisol with cortisol levels of other commonly used methods and found that "saliva and serum levels both reflect acute levels, urine represents cortisol secretion during one day, whereas hair cortisol levels represent levels during 1 - 2 months" and commented that regarding hair cortisol, "the levels are not affected by acute stress" [62].

The Health Canada Study methods for hair sample collection and cortisol analysis are described in section 2. Hair treatment and enzyme-linked immunosorbent assay (ELISA) [29]. The ELISA methodology was used in accordance with a previously established protocol described by Pereg et al. [69]. Due to the potential for false positives, indications are that in some circumstances results of 
the ELISA test are presumptive, requiring confirmation using a method with a higher degree of specificity, such as gas chromatography-mass spectrometry (GC-MS) or liquid chromatography-tandem mass spectrometry (LC-MS/MS [70] [71] [72] [73].

For the interest of readers and researchers, the ELISA methodology was examined by the Honourable Justice Susan Lang as the result of child protection and criminal proceedings by child protection agencies seeking to determine if a parent or caregiver had used drugs or alcohol [73]. A statement of claim for a lab class action has been issued [74]. In addition, since a fetus is considered at risk from exposure to the Zika virus, physicians were alerted of some false positive results from the Zika MAC-ELISA [71]. The CDC (Centers for Disease Control and Prevention) provided a fact sheet for healthcare providers which included an advisory that confirmation of "positive or equivocal results requires additional testing by $\mathrm{CDC}$ or by qualified laboratories designated by $\mathrm{CDC}$ and in consultation with CDC ..." [72].

ELISA has been compared to other assay methods. For example, a study in children indicates that when compared to liquid chromatography-mass spectrometry (LCMS), ELISA-based assays "showed greater sensitivity for measuring hair cortisol levels" [75]. However, regarding consistency of extraction methods, the study found:

A lack of consistency in hair cortisol data from different laboratories using single extraction methods contributes to greater variability and inconsistency in the reported reference ranges, an inability to perform quantitative meta-analyses, or to examine age-related changes [75].

Slominski et al. [75] indicate further refinements in hair cortisol analysis may be required "before the data reported in the clinical literature can be considered precise enough for clinical decision-making, or for establishing reference ranges for different age groups" and propose enhanced analytical methods.

Based on the methods described in Michaud et al. [29] it appears confirmation testing was not performed. If confirmation testing were indicated but not performed on positive hair cortisol results, there could be perceived uncertainty of hair cortisol results.

While these discussions relate to factors such as forensic and legal requirements, the challenges associated with capturing acute or chronic cortisol values, and the potential for lack of consistency during analysis, there is an opportunity to enhance future WT investigations related to stress outcomes. These opportunities include comparing ELISA with other analytical methods, to consider measurements that contribute towards eliciting chronic and acute values, and sampling some subjects using a method with a higher degree of specificity than ELISA and comparing results.

\subsection{Availability of Raw Data}

The Health Canada Study announcement of 2012 advised: 
Specific details related to the study locations, timing and survey components will be made available on the Health Canada website upon completion of the research in order to protect the integrity of the study [23].

In addition, the summary of results publicly advised that the raw data originating from the study were available to Canadians, other jurisdictions and interested parties through a number of sources such as the Health Canada website (noise data), open access to publications in scientific journals and conference presentations, and the Federal Resource Data Center (RDC) [25].

Regarding the RDC process, the complete file of un-interpreted, i.e., raw data, appears unavailable to researchers. For example, in 2016, an Ontario research team entered into a contractual agreement with Statistics Canada to research the Health Canada Study findings [76]. The project team members were subject to all the conditions and penalties of Statistics Canada employees including fines and/or imprisonment for breach of confidentiality. Research requirements included access to the complete and unaltered raw data file. While some of the raw data were available, other data were the property of Health Canada and were not available through the RDC. In an effort to obtain the required raw data elements, federal public record requests were submitted to the Health Canada ATIP (Access to Information and Privacy) system. In response, Health Canada stated these were "totally exempted from disclosure pursuant to the following provisions of the Act... third party financial, commercial, scientific or technical information given in confidence to the government" [77] [78].

It appears another research team which assessed Health Canada's findings experienced a similar limitation. The researchers comment:

Our analysis has limitations. Raw sound data were not available to us with the Community Noise and Health dataset. Only background-level noises and the modelled wind turbine sound were. Therefore, it was not possible to model sound using alternative methods, such as using G-weighted modelled sound, which would better account for low frequency sound waves ... [79].

Justice Sébastien Grammond, a Canadian Federal Court Judge [80] ruled on a case involving a researcher's request for clinical trial data in order to conduct a systematic review of a pharmaceutical product. When Health Canada considered it "confidential business information" and would not provide these data without a confidentiality agreement, the researcher took the case to Canada's Federal Court. Justice Grammond indicated Health Canada's stance "unreasonable" and issued "an order of mandamus requiring Health Canada to grant Dr. Doshi's request and to communicate the information sought" [80].

While the Federal Court case relates to clinical trial data, it appears in principle there is a potential to apply its ruling to the Health Canada Study raw data file.

Michaud et al. encourage "constructive criticism of scientific research" and acknowledges this "often stimulates improvements in future studies" [33]. In addition, it appears a revised data file is publically available through the Statis- 
tics Canada Research Data Centres [34]. However, at this time it is unknown whether the revised data file will include access to the complete and unaltered raw data file or whether it would be limited in its content.

While researchers can comment on Health Canada Study's interpreted and published papers, the lack of a centralized custodian of the complete raw data file hinders the ability to "independently reproduce the Health Canada findings and to explore opportunities to confirm and/or provide additional contributions and insights regarding this complex topic" [76].

For the interest of readers, a status update is available through the link provided at Krogh and Aramini [76].

\subsection{Research/Knowledge Gaps and Evolving Research Methods}

WT related research and knowledge gaps have been acknowledged by researchers and others [1] [9] [12] [37] [81] [82] [83] [84]. Health Canada identified one of the challenges related to "competition for resources for research and assessment" which leaves "many health concerns and potential risks unaddressed" [83]. In response to knowledge and research gaps, the World Health Organization (WHO) announced the development of environmental noise guidelines for the European Region which includes WT: “... the guidelines highlight critical data and research gaps to be addressed in future studies" [84].

Differences in study design, the absence of longitudinal studies and inter-subject variability contribute towards WT research challenges. Sensitivities to audible and inaudible noise (infrasound), age related vulnerabilities (elderly and fetus to youth), disease states and pre-existing medical conditions, variability of exposure (chronic verses acute), lack of sufficient statistical power due to low population densities to detect small changes in risk factors, and social issues also contribute to research challenges. Additional factors include potential effects of WT related LFN/infrasound emissions and electromagnetic energy, operational variables, use of calculated noise models and a variety of local or state noise guidelines. Combined, these factors can make it difficult to compare research results and health outcomes.

Since the Health Canada Study design of 2012, methods have evolved. Objective measurements have included the use of advanced methods and technologies such as: a time stratified, case-crossover design [85]; MRI technology to document changes of brain activity when exposed to infrasound from WT [86]; verification of the physiological impact by ECG (electrocardiogram) [20] and brain waves by electroencephalogram (EEG) associated with low frequency/infrasound [87]; and a double blind provocation case control pilot [88].

These methods should be considered during future investigations of WT.

\section{Discussion: What Is the Way Forward-More Research, Prevention, Precaution?}

Internationally, governments, authorities, WT energy developers and many of 
those including occupational workers and families who are currently exposed, or in the future expect to be exposed to WT facilities, have an interest in the Health Canada Study findings.

Some people living in proximity to WT report a variety of adverse health effects such as sleep disturbance, body sensations, anxiety, tinnitus, noise annoyance, altered quality of life and health, excessive tiredness, headaches, migraines, hearing problems, heart palpitations, anxiety, stress, depression and social issues. The authors of Colby et al. conducted an Expert Panel review for the American Wind Energy Association and Canadian Wind Energy Association and determined that the symptoms of "wind turbine syndrome" described by Pierpont 2009 are not new, have been published previously in the context of "annoyance" and are the "well-known stress effects of exposure to noise" [4].

Fredianelli et al. observe with the increasing installation of WT there is an increase towards WT noise and as a result the "scientific community has promptly responded, increasing the studies and the social surveys in order to better understand the cause of disturbance and the indicators that relate to it" [89]. WHO indicates that reliance on wind energy in Europe has increased which has "resulted in higher public annoyance in the EU" and announced the development of new environmental noise guidelines including:

... consideration of new evidence associating environmental noise exposure with health outcomes, such as annoyance, cardiovascular effects, obesity and metabolic effects (such as diabetes), cognitive impairment, sleep disturbance, hearing impairment and tinnitus, adverse birth outcomes, quality of life, mental health, and wellbeing ... [84]

The release of WHO noise guidelines indicate there "are serious issues with noise exposure assessment related to wind turbines" and that further work is needed to "assess fully the benefits and harms of exposure to environmental noise from wind turbines and to clarify whether the potential benefits associated with reducing exposure to environmental noise for individuals living in the vicinity of wind turbines outweigh the impact on the development of renewable energy policies in the WHO European Region" [[90] Table 42].

In Ontario Canada, numerous WT related complaints have been filed by neighbors who live in proximity to WT. For example, WCO (Wind Concerns Ontario) obtained government records provided through requests under the province of Ontario's Freedom of Information legislation. The records revealed that between 2006 to the end of 2016, Ontario families who live near operating WT projects submitted 4562 Incident Reports of WT noise complaints. Thirty-five percent of these reports contained explicit references by government staff to reported adverse health effects which were related to WT noise emissions [91]. Despite unresolved knowledge gaps and official records of complaints, WT projects continue to operate and others continue to be proposed near family homes [40] [92].

Some of the citations in this paper encourage the need for additional WT 
studies [9] including proposals for what should be studied. Suggestions include: to consider quantification of amplitude modulation and tonality [1] [32]; to study occupational "work-related injury and accident rates, and health outcomes in later life cycle phases" [5]; to conduct epidemiological and laboratory research by health professionals and acousticians [14]; to research occupational worker exposure [15] and confirm occupational exposure results [18]; to focus on alternative exposures other than noise [79]; to intentionally explore the factors regarding differences in community responses to WT noise [55]; to conduct experimental and observational studies regarding wind turbine noise and health [2]; to determine the distances that risks become negligible [21]; to replicate findings [85]; to assess health status before and after WT development [79] [81]; to conduct longitudinal studies [64] and require further (especially longitudinal) studies to substantialize findings [87].

In response to comments made by some, Health Canada summarized the strengths and limitations of the Health Canada Study, identified issues associated with third party re-evaluation and reinforced the limits for applying results:

... one must avoid potential "apples to oranges" comparisons as the sample population in the CNHS is not generalizable. This has been identified by the CNHS authors as one of the limitations (i.e., caution on extrapolation beyond the study sample because the communities in the study may have important differences when compared to others in Canada, or elsewhere) [33].

Health Canada has also acknowledged that the Health Canada Study will "not permit any conclusions to be made with respect to causality" [37]. In the province of Ontario, Canada legislation requires community members who wish to appeal an approval of a WT project must prove the project "will cause serious harm to human health" prior to the start up of WT operations [93]. Small rural communities with a low population density face financial and scientific burdens. Proof of causality is rare in human health and ranks:

$\ldots$ at about $95 \%$ to $99 \%$ certainty and is rarely possible for biological systems; the Precautionary Principle ranks at the about the 50\% medium level, consistent with civil and some administrative law; and environmental protection has a low level of certainty (10\% to $30 \%)$ [94].

During a 2005 conference presentation, Health Canada commented that releases from products and technologies (which included renewables) can alter environmental quality which could result in unexpected risks to health. The presentation concluded:

We cannot afford to wait until the health of Canadians is affected before we act. We have the means, tools and knowledge to become proactive in protecting the health of our citizens, in particular those most at risk [95].

Health Canada advised during a presentation to the Health Canada SAB that it would: 
Place hold on Guideline finalization: HC will explore research options and release guidelines only when knowledge gaps are filled [96].

If the intention is to prove causality, as with other complex research this would take many years. In the meantime, more people are at risk of harm.

WHO 1999 [97] provides "environmental management principles on which government policies, including noise management policies, can be based":

1) The precautionary principle. In all cases, noise should be reduced to the lowest level achievable in a particular situation. Where there is a reasonable possibility that public health will be damaged, action should be taken to protect public health without awaiting full scientific proof.

2) The polluter pays principle. The full costs associated with noise pollution (including monitoring, management, lowering levels and supervision) should be met by those responsible for the source of noise.

3) The prevention principle. Action should be taken where possible to reduce noise at the source. Land-use planning should be guided by an environmental health impact assessment that considers noise as well as other pollutants.

Formal adoption and application of these principals by authorities and regulators would contribute towards protecting families and occupational workers from risk factors while living or working near WT.

A critical question is "Why are some people vulnerable to WT noise while others are not?" Endeavouring to determine whether or not people exposed to WT noise are affected, and determining the degree of an adverse effect is complex. As is the case with any potentially pathogenic stimulus, people are not equally affected. When adverse effects do occur they may be acute and transient, recurrently episodic and/or chronic. It is therefore essential to utilize sensitive measurements which can not only detect a subset of disturbed people but also consider the pattern of responses. Time sensitive measurements would assist with determining whether the reported adverse effects occur at night during sleep, during waking hours, or during both, and while seeking potential correlations with the nature of the noise exposure.

WT health related investigations could be conducted by multidisciplinary teams centered in medical facilities and staffed by physicians, clinicians, acousticians and other specialists. Full spectrum noise measurements and EMF emissions could be taken in homes and occupational settings of those reporting adverse health effects. Subjects could be monitored over time through long term surveillance. Family physicians could refer patients suspected of being affected by WT to a centralized facility. The WT investigative protocols by McMurtry et al. [98] and the Austrian Medical Association [99] could provide assistance during these investigations.

\section{Conclusions}

To conclude, this paper presents a contemporary example of the research challenges associated with WT with the goal of participating in scientific dialogue 
and contributing towards enhanced methods for future investigations. While exploring some of the limitations/uncertainties and commenting on some of the methodologies employed by Health Canada, this paper acknowledges the Health Canada Study design had a number of strengths as noted by Michaud et al. 2018 [33]. This paper also concurs with Health Canada's advisories that the Health Canada Study results will not be "definitive on their own"; the design will not permit conclusions regarding "causality"; and results may not be generalized beyond the sample studied in Ontario and Prince Edward Island, Canada.

Given Health Canada's advisories, the unresolved research and knowledge gaps, the limitations and uncertainties presented in this paper, reliance of Health Canada Study results to support the safety of WT in literature and during judicial processes should be considered with caution in predicting or understanding the health risks of WT noise.

\section{Acknowledgements}

The authors declare they had no actual or potential competing financial interests, received no funding and volunteered their time during the research and writing of this paper. Authors Krogh, Nissenbaum and James are volunteers and members of the Board of Directors of the Society for Wind Vigilance, a self funded, Federally Incorporated Not-For-Profit organization. Author Krogh is a volunteer on the Board of Directors for the Magentica Research Group, a self-funded Federally Incorporated Not-For-Profit organization. Author Dumbrille is a volunteer, Chair and member of the Board of Directors of a Federally Incorporated Not-For-Profit organization. In all cases, Board members volunteer their time and do not receive any financial remuneration for their services. Health Canada is acknowledged for considering the public concern for potential health impacts and conducting its wind turbine noise and health study.

This article is dedicated to the families and wind energy occupational workers from around the world who are reporting adverse health effects associated with the presence of industrial scale wind turbines in proximity to their living and work environments. In addition, we thank the peer reviewers who volunteered their time, professional expertise and provided insightful and helpful comments during the review process.

\section{Financial Support and Sponsorship}

None.

\section{Conflicts of Interest}

There are no conflicts of interest.

\section{References}

[1] CCA (2015) Council of Canadian Academies. Understanding the Evidence. The Expert Panel on Wind Turbine Noise and Human Health, Table 7.1. 
https://www.scienceadvice.ca/reports/understanding-the-evidence-wind-turbine-no ise/

[2] Onakpoya, I.J., O’Sullivan, J., Thompson, M.J. and Heneghana, C.J. (2015) The Effect of Wind Turbine Noise on Sleep and Quality of Life: A Systematic Review and Meta-Analysis of Observational Studies. Environment International, 82, 1-9. http://www.sciencedirect.com/science/article/pii/S0160412015001051 https://doi.org/10.1016/j.envint.2015.04.014

[3] Jeffery, R.D., Krogh, C. and Horner, B. (2013) (Commentary) Adverse Health Effects of Industrial Wind Turbines. Canadian Family Physician, 59, 473-475. https://www.ncbi.nlm.nih.gov/pmc/articles/PMC3653647/

[4] Colby, W., Dobie, R., Leventhall, G., Lipscomb, D., McCunney, R., Seilo, M. and Søndergaard, B. (2009) Wind Turbine Sound and Health Effects: An Expert Panel Review. Prepared for American Wind Energy Association and Canadian Wind Energy Association.

http://www.canwea.ca/pdf/talkwind/Wind_Turbine_Sound_and_Health_Effects.pd $\underline{\mathrm{f}}$

[5] Freiberg, A., Schefter, C., Girbig, M., Murta, V.C. and Seidler (2018) Health Effects of Wind Turbines in Working Environments: A Scoping Review. Scandinavian Journal of Work Environment \& Health, 44, 351-369.

https://www.ncbi.nlm.nih.gov/pubmed/?term=Health+effects+of+wind+turbines+i n+working+environments+\%E2\%80\%93+a+scoping+review

[6] Kageyama, T., Yano, T., Kuwano, S., Sueoka, S. and Tachibana, H. (2016) Exposure-Response Relationship of Wind Turbine Noise with Self-Reported Symptoms of Sleep and Health Problems: A Nationwide Socioacoustic Survey in Japan. Noise \& Health, 18, 53-61. https://www.ncbi.nlm.nih.gov/pubmed/26960782 https://doi.org/10.4103/1463-1741.178478

[7] Acoustic Group (2014) Results of an Acoustic Testing Program: Cape Bridgewater Wind Farm.

https://www.wind-watch.org/documents/results-of-an-acoustic-testing-program-ca pe-bridgewater-wind-farm/

[8] Havas, M. and Colling, D. (2011) Wind Turbines Make Waves: Why Some Residents near Wind Turbines Become Ill. Bulletin of Science Technology \& Society, 31, 414. http://journals.sagepub.com/doi/abs/10.1177/0270467611417852 https://doi.org/10.1177/0270467611417852

[9] Krogh, C.M.E., Gillis, L., Kouwen, N. and Aramini, J. (2011) WindVOiCe, a Self-Reporting Survey: Adverse Health Effects, Industrial Wind Turbines, and the Need for Vigilance Monitoring. Bulletin of Science Technology \& Society, 31, 334. http://bst.sagepub.com/content/31/4/334 https://doi.org/10.1177/0270467611412551

[10] Pierpont, N. (2009) Wind Turbine Syndrome: A Report on a Natural Experiment. K-Selected Books, Santa Fe, NM.

[11] Jeffery, R.D., Krogh, M.E. and Horner, B. (2014) (Review) Industrial Wind Turbines and Adverse Health Effects. Canadian Journal of Rural Medicine, 19, 21-26. http://www.ncbi.nlm.nih.gov/pubmed/24398354

[12] Krogh, C.M.E. (2011) Industrial Wind Turbine Development and Loss of Social Justice? Bulletin of Science Technology \& Society, 31, 321. http://journals.sagepub.com/doi/abs/10.1177/0270467611412550 https://doi.org/10.1177/0270467611412550

[13] Ripley Group. Legislative Assembly of Ontario First Session, 39th Parliament. Offi- 
cial Report Journal of Debates (Hansard), Wednesday 15 April 2009. Standing Committee on Green Energy and Green Economy Act, 2009. David Orazietti, Chair, P. G-547.

https://www.ola.org/en/legislative-business/committees/general-government/parlia ment-39/transcripts/committee-transcript-2009-apr-15\#P1296_397237

[14] Ambrose, S.E., Rand, R.E. and Krogh, C.M.E. (2012) Wind Turbine Acoustic Investigation: Infrasound and Low-Frequency Noise: A Case Study. Bulletin of Science Technology \& Society.

http://bst.sagepub.com/content/early/2012/07/30/0270467612455734

[15] Rand, R.W., Ambrose, S.E. and Krogh, C.M.E. (2011) Occupational Health and Industrial Wind Turbines: A Case Study. Bulletin of Science Technology \& Society, 31, 359. https://doi.org/10.1177/0270467611417849 http://bst.sagepub.com/content/31/5/359

[16] Swinbanks, M. (2015) Direct Experience of Low-Frequency Noise and Infrasound within a Windfarm Community. 6th International Meeting on Wind Turbine Noise, Glasgow, 20-23 April 2015.

https://www.wind-watch.org/documents/direct-experience-of-low-frequency-noiseand-infrasound-within-a-windfarm-community/

[17] Abbasi, M., Monazzam, M.R., Ebrahim, M.H., Zakerian, S.A., Dehghan, S.F. and Akbarzadeh, A. (2016) Assessment of Noise Effects of Wind Turbine on the General Health of Staff at Wind Farm of Manjil, Iran. Journal of Low Frequency Noise, Vibration and Active Control, 35, 91-98.

http://journals.sagepub.com/doi/abs/10.1177/0263092316628714 https://doi.org/10.1177/0263092316628714

[18] Abbasi, M., Monazzam, M.R., Akbarzadeh, A., Zakerian, S.A. and Ebrahim, M.H. (2015) Impact of Wind Turbine Sound on General Health, Sleep Disturbance and Annoyance of Workers: A Pilot-Study in Manji Wind Farm, Iran. Journal of Environmental Health Science \& Engineering, 13, 71.

https://jehse.biomedcentral.com/articles/10.1186/s40201-015-0225-8 https://doi.org/10.1186/s40201-015-0225-8

[19] Abbasi, M., Monnazzam, M.R., Zakerian, S.A. and Yousefzadeh, A. (2015) Effect of Wind Turbine Noise on Workers' Sleep Disorder: A Case Study of Manjil Wind Farm in Northern Iran. Fluctuation and Noise Letters, 14, Article ID: 1550020.

https://www.worldscientific.com/doi/abs/10.1142/S0219477515500200 https://doi.org/10.1142/S0219477515500200

[20] Inagaki, T., Li, Y. and Nishi, Y. (2015) Analysis of Aerodynamic Sound Noise Generated by a Large Scaled Wind Turbine and Its Physiological Evaluation. International Journal of Environmental Science and Technology, 12, 1933-1944.

https://link.springer.com/article/10.1007\%2Fs13762-014-0581-4 https://doi.org/10.1007/s13762-014-0581-4

[21] Nissenbaum, M.A., Aramini, J.J. and Hanning, C.D. (2012) Effects of Industrial Wind Turbine Noise on Sleep and Health. Noise \& Health, 14, 237-243.

https://www.ncbi.nlm.nih.gov/pubmed/?term=Effects+of+industrial+wind+turbine + noise+on+sleep+and+health https://doi.org/10.4103/1463-1741.102961

[22] Michaud, D.S., Keith, S.E., Feder, K., Soukhovtsev, V., Marro, L., Denning, A., et al. (2013) Self-Reported and Objectively Measured Health Indicators among a Sample of Canadians Living within the Vicinity of Industrial Wind Turbines: Social Survey and Sound Level Modelling Methodology. Noise News International, 21, 122-131. https://docs.wind-watch.org/NNI_2013_Dec_HC-methodology.pdf 
https://doi.org/10.3397/1.37023117

[23] Health Canada. Environmental \& Workplace Health (July 10, 2012) Notice to Stakeholders-Health Canada Wind Turbine Noise and Health Study.

https://www.canada.ca/en/health-canada/services/environmental-workplace-health/ consulta-

tions/notice-stakeholders-health-canada-wind-turbine-noise-health-study-2012-hea lth-canada-consultation.html

[24] Michaud, D.S., Feder, K., Keith, S.E., Voicescu, S.A., Marro, L., Than, J., et al. (2016) Exposure to Wind Turbine Noise: Perceptual Responses and Reported Health Effects. The Journal of the Acoustical Society of America, 139, 1443-1454.

https://asa.scitation.org/doi/10.1121/1.4942391 https://doi.org/10.1121/1.4942391

[25] Health Canada. Environmental and Workplace Health (November 6, 2014) Wind Turbine Noise and Health Study: Summary of Results.

https://www.canada.ca/en/health-canada/services/environmental-workplace-health/ noise/wind-turbine-noise/wind-turbine-noise-health-study-summary-results.html

[26] Keith, S.E., Feder, K., Voicescu, S.A., Soukhovtsev, V., Allison, D., Tsang, J., et al. (2016) Wind Turbine Sound Power Measurements. The Journal of the Acoustical Society of America, 139, 1431-1435.

https://asa.scitation.org/doi/full/10.1121/1.4942405

https://doi.org/10.1121/1.4942405

[27] Keith, S.E., Feder, K., Voicescu, S.A., Soukhovtsev, V., Allison, D., Tsang, J., et al. (2016) Wind Turbine Sound Pressure Level Calculations at Dwellings. The Journal of the Acoustical Society of America, 139, 1436-1442.

https://asa.scitation.org/doi/abs/10.1121/1.4942404 https://doi.org/10.1121/1.4942404

[28] Michaud, D.S., Feder, K., Keith, S.E., Voicescu, S.A., Marro, L., Than, J., et al. (2016) Effects of Wind Turbine Noise on Self-Reported and Objective Measures of Sleep. Sleep, 39, 97-109.

https://www.researchgate.net/publication/283447420_Effects_of_Wind_Turbine_N oise_on_Self-Reported_and_Objective_Measures_of_Sleep https://doi.org/10.5665/sleep.5326

[29] Michaud, D.S., Feder, K., Keith, S.E., Voicescu, S.A., et al. (2016) Self-Reported and Measured Stress Related Responses Associated with Exposure to Wind Turbine Noise. The Journal of the Acoustical Society of America, 139, 1467-1479.

https://asa.scitation.org/doi/abs/10.1121/1.4942402 https://doi.org/10.1121/1.4942402

[30] Michaud, D.S., Keith, S.E., Feder, K., Voicescu, S.A., Marro, L., Than, J., et al. (2016) Personal and Situational Variables Associated with Wind Turbine Noise Annoyance. The Journal of the Acoustical Society of America, 139, 1455-1466. https://asa.scitation.org/doi/abs/10.1121/1.4942390 https://doi.org/10.1121/1.4942390

[31] Voicescu, S.A., Michaud, D.S., Feder, K., Marro, L., Than, J., Guay, M., et al. (2016) Estimating Annoyance to Calculated Wind Turbine Shadow Flicker Is Improved When Variables Associated with Wind Turbine Noise Exposure Are Considered. The Journal of the Acoustical Society of America, 139, 1480-1492.

https://asa.scitation.org/doi/abs/10.1121/1.4942403 https://doi.org/10.1121/1.4942403

[32] Feder, K., Michaud, D.S., Keith, S.E., Voicescu, S.A., Marro, L., Than, J., et al. (2015) An Assessment of Quality of Life Using the WHOQOL-BREF among Participants 
Living in the Vicinity of Wind Turbines. Environmental Research, 142, 227-238. https://www.sciencedirect.com/science/article/pii/S0013935115300189 https://doi.org/10.1016/j.envres.2015.06.043

[33] Michaud, D.S., Feder, K., Voicescu, S.A., Marro, L., Than, J., Guay, M., Lavigne, E., et al. (2018) Clarifications on the Design and Interpretation of Conclusions from Health Canada's Study on Wind Turbine Noise and Health. Acoustics Australia, 46, 99-110. https://link.springer.com/article/10.1007\%2Fs40857-017-0125-4 https://doi.org/10.1007/s40857-017-0125-4

[34] Michaud, D.S., Feder, K., Keith, S.E., Voicescu, S.A., Marro, L., Than, J., Guay, M., Denning, A., et al. (2018) Corrigendum: Effects of Wind Turbine Noise on Self-Reported and Objective Measures of Sleep. Sleep, 41, zsy037.

https://academic.oup.com/sleep/article/41/5/zsy037/4954221 https://doi.org/10.1093/sleep/zsy037

[35] Michaud, D.S., Feder, K., Keith, S.E., Voicescu, S.A., et al. (2016) Erratum: Exposure to Wind Turbine Noise: Perceptual Responses and Reported Health Effects [J. Acoust. Soc. Am. 139(3), 1443-1454 (2016)]. The Journal of the Acoustical Society of America, 139, 2457. https://asa.scitation.org/doi/10.1121/1.4964754

[36] Michaud, D.S., Keith, S.E., Feder, K., Voicescu, S.A., et al. (2016) Erratum: Personal and Situational Variables Associated with Wind Turbine Noise Annoyance [J. Acoust. Soc. Am. 139(3), 1455-1466 (2016)]. The Journal of the Acoustical Society of America, 140, 2234. https://doi.org/10.1121/1.4963838

[37] Health Canada. Environmental \& Workplace Health (2013) Consultations. Health Impacts and Exposure to Sound from Wind Turbines: Updated Research Design and Sound Exposure Assessment.

https://www.canada.ca/en/health-canada/services/environmental-workplace-health/ consultations/health-impacts-exposure-sound-wind-turbines-updated-research-design-soun d-exposure-assessment.html

[38] MOECC (April 2018) Ministry of Environment and Climate Change, Ontario, Canada. Personal Correspondence.

[39] Jasper County Planning \& Development (September 21, 2018) Review of Proposed Revisions to the Jasper County Zoning Ordinance Section 20.30.170 WFO District Development Standards. Rensselaer, Indiana, USA.

[40] AUC (Alberta Utilities Commission November 22, 2017) AUC 22563, Volume 2. Proceeding ID No. 22563. Capital Power's Request for Approval to Construct and Operate a 148-Megawatt Wind Power Plant and a 240-Kv Substation to be called Goldeye 620s Substation, Collectively Designated as Halkirk 2 Wind Power Project In the County of Paintearth. November 22, 2017, Red Deer, Alberta. Testimony by C. Ollson (For Capital Power Corporation), previously sworn/affirmed.

[41] Brown County Human Services Commission. Brown County Special Event (September 12, 2017). Wisconsin, USA. Presentation by Dr. Robert McCunney.

http://bccrwe.com/27

https://www.youtube.com/watch?v=2kvoZO-DEho\&feature=youtu.be

[42] State of New York Department of Public Service (July 20, 2017) In the Matter of: Case 14-F-0490, Application by Cassadaga Wind LLC for a Certificate of Environmental Compatibility and Public Need Pursuant to Article 10 of the New York State Public Service Law for the Cassadaga Wind Project, Towns of Charlotte, Cherry Creek, Arkwright, and Stockton, Chautauqua County. Evidentiary Hearing-14-F-0490-7-20-2017. Thursday July 20, 2017. Sinclairville, New York. Dakin P. Lecakes, DPS, Administrative Law Judge and P. Nicolas Garlick, DEC Adminis- 
trative Law Judge. Sworn testimony of Dr. Robert McCunney.

[43] Commonwealth of Massachusetts Superior Court (2016) Case No. 1472CV0003. Vol. 5. Barnstable, ss. Superior Court. Town of Falmouth, Plaintiff, vs. Town of Falmouth Zoning Board of Appeals, and Matthew Mcnamara, Patricia Johnson, Kenneth Foreman, Edwin Zylinski, David Haddad and Mark Cool as members of the Falmouth Zoning Board of Appeals; and Barry Funfar and Diane Funfar, Defendants. Before the Honorable Cornelius J. Moriarty II, Associate Justice of the Superior Court (November 23, 2016) Barnstable, Massachusetts Vol 5. p. 16 1. 20. Sworn testimony by Dr Robert McCunney.

[44] State of Vermont Public Utility Commission (December 2, 2016) Sworn Testimony by Christopher Ollson, PhD. Ollson Environmental Health Management. Addressing Wind Turbine Health Concerns.

http://puc.vermont.gov/sites/psbnew/files/doc_library/rulemaking-5700-dps-oehmpresentation-12-2-16.pdf

[45] ERT (Environmental Review Tribunal May 11, 2015) Ontario, Canada. Proceeding Commenced under Section 142.1(2) of the Environmental Protection Act, R.S.O. 1990, c.E.19, as amended Douglas Edward Dingeldein v Director, Ministry of the Environment and Climate Change. Case No. 15-011. Subject of appeal: Renewable Energy Approval for Grey Highlands Zero Emission People Wind Farm. Sworn testimony by Dr Robert McCunney.

[46] Superior Court of Justice Divisional Court-Ontario (2014) Dixon v. Director, Ministry of the Environment, 2014 ONSC 7404 Divisional Court Files Nos.: 2055/14, 2056/14 and 2073/14. Date: 20141229 Marrocco A.C.J.S.C., J. Henderson and D. Brown JJ. Court File No. 2055/14, between: Scotty Dixon, Jennifer Dixon, Thomas Ryan and Catherine Ryan Appellants and the Director, Ministry of the Environment and St. Columban Energy LP Respondents. Court File No. 2056/14 and between: Shawn Drennan and Tricia Drennan Appellants and The Director, Ministry of the Environment and K2 Wind Ontario Inc., operating as K2 Wind Ontario Limited Partnership Respondents, Court File No. 2073/14 and between: Kenneth George Kroeplin and Sharon Anne Kroeplin Appellants and The Director, Ministry of the Environment and SP Armow Wind Ontario GP Inc. as general partner for and on behalf of SP Armow Wind Ontario LP Respondents. Heard at London: November 17, 18, 19 and 20, 2014.

[47] MG Acoustics (February, 2014) Analysis, Modeling, and Prediction of Infrasound and Low Frequency Noise from Wind Turbine Installation. Phase 1: PEI Site Final Report. https://docs.wind-watch.org/WT-ILFN-Phase-1-PE-Final-Report-Redacted.pdf

[48] MG Acoustics (February, 2014) Analysis, Modeling, and Prediction of Infrasound and Low Frequency Noise from Wind Turbine Installation. Phase 2: Southern Ontario Site. Final Report. https://docs.wind-watch.org/WT-ILFN-Phase-2-ON-Final-Report-Redacted.pdf

[49] Barlas, E., Zhu, W.J., Shen, W.Z. and Andersen, S.J. (2016) Wind Turbine Noise Propagation Modelling: An Unsteady Approach. The Science of Making Torque from Wind, (TORQUE 2016) IOP Publishing. Journal of Physics: Conference Series, 753, Article ID: 022003.

http://orbit.dtu.dk/files/127151921/Wind_turbine_noise_propagation_modelling.p df

[50] Iannace, G. (2018) Wind Turbines Noise Measurements inside Homes. Building Acoustics, 25, 339-350.

http://journals.sagepub.com/action/doSearch?AllField=Wind+turbines+noise+mea 
surements+inside+homes\&SeriesKey=buaa https://doi.org/10.1177/1351010X18792884

[51] Schmidt, J.H. and Klokker, M. (2014) Health Effects Related to Wind Turbine Noise Exposure: A Systematic Review. PLoS ONE, 9, e114183.

https://journals.plos.org/plosone/article?id=10.1371/journal.pone.0114183 https://doi.org/10.1371/journal.pone.0114183

[52] Gortsasa, T.V., Triantafyllidis, T., Chrisopoulosa, S. and Polyzosb, D. (2017) Numerical Modelling of Micro-Seismic and Infrasound Noise Radiated by a Wind Turbine. Soil Dynamics and Earthquake Engineering, 99, 108-123. https://www.sciencedirect.com/science/article/pii/S026772611730297X https://doi.org/10.1016/j.soildyn.2017.05.001

[53] AAT, Administrative Appeals Tribunal (December 4, 2017) Waubra Foundation vs ACNC. Decision \& Reasons, Summary of the Effect of the Medical and Scientific Evidence.

https://waubrafoundation.org.au/wp-content/uploads/2017/12/Decision-4-Dec-17.p $\underline{\mathrm{df}}$

[54] DEIF Inc. (nd) SCADA Systems for Wind Turbine Control. https://www.deif.com/wind-power/solutions/scada-systems

[55] Michaud DS (May 26, 2016) An Evaluation of How Nightly Variations in Wind Turbine Noise Levels Influence Wrist Actigraphy Measured Sleep Patterns. Abstract. 171 st Meeting of the Acoustical Society of America, Salt Lake City, Utah, USA.

[56] Michaud, D.S. (May 25, 2016) An Evaluation of How Nightly Variations in Wind Turbine Noise Levels Influence Wrist Actigraphy Measured Sleep Patterns. Slide Presentation. 171 st Meeting of the Acoustical Society of America, Salt Lake City, Utah, USA.

[57] Penton, R.L. S. and Arnold, L. (2016) Principal, Acoustics Noise and Vibration. Novus Environmental, January 4, 2016. CAW Wind Turbine Acoustical Measurements Saugeen Shores, Ontario.

[58] Bray, W. and James, R. (2011) Dynamic Measurements of Wind Turbine Acoustic Signals, Employing Sound Quality Engineering Methods Considering the Time and Frequency Sensitivities of Human Perception. NOISE-CON 2011, Portland, Oregon, USA, 25-27 July 2011.

https://docs.wind-watch.org/Bray-James-11-07-25-Dynamic-measurement-of-wind -turbine-noise.pdf

[59] B. Walker, George, F., Hessler, D.M., Rand, R. and Schomer, P. (2012) A Cooperative Measurement Survey and Analysis of Low Frequency and Infrasound at the Shirley Wind Farm in Brown County, Wisconsin. Report Number 122412-1 (Issued: December 24, 2012). Cooperative Measurement Survey.

https://puc.sd.gov/commission/dockets/electric/2018/EL18-003/testimony/testimon y/mogen/Noise\%20Exhibit\%204.pdf

[60] Persson Waye, K., Clow, A., Edwards, S., Hucklebridge, F. and Rylandera, R. (2003) Effects of Nighttime Low Frequency Noise on the Cortisol Response to Awakening and Subjective Sleep Quality. Life Sciences, 72, 863-875.

http://docs.wind-watch.org/Persson-Waye-LFN-cortisol-2002.pdf https://doi.org/10.1016/S0024-3205(02)02336-6

[61] Karlan, J.L., Frostell, A., Theodorsson, E. and Faresjö, T. (2011) Cortisol in Hair Measured in Young Adults-A Biomarker of Major Life Stressors? BMC Clinical Pathology, 11, 12. 
https://bmcclinpathol.biomedcentral.com/articles/10.1186/1472-6890-11-12 https://doi.org/10.1186/1472-6890-11-12

[62] Sauvé, B., Koren, G., Walsh, G., Tokmakejian, S. and Van Uum, S.H. (2007) Measurement of Cortisol in Human Hair as a Biomarker of Systemic Exposure. Clinical and Investigative Medicine, 30, E183-E191.

https://www.researchgate.net/publication/5951333_Measurement_of_cortisol_in_h uman_Hair_as_a_biomarker_of_systemic_exposure

[63] Albar, W.F., Russell, E.W., Koren, G., Rieder, M.J. and van Umm, S.H. (2013) Human Hair Cortisol Analysis: Comparison of the Internationally-Reported ELISA Methods. Clinical and Investigative Medicine, 36, E312-E316.

https://www.ncbi.nlm.nih.gov/pubmed/24309228

[64] Pieterson, B., Bower, T. and Michaud, D. (February 12, 2012) Health Canada's Policy and Research Approach to Wind Turbines. Healthy Environments and Consumer Safety Branch, Health Canada. Science Advisory Board (SAB) Meeting Proceedings.

https://www.canada.ca/en/health-canada/services/science-research/reports-publicat ions/science-advice-decision-making/science-advisory-board-meeting-february-1-2 -2012.html

[65] Lee, D.Y., Kim, I.E. and Choi, M.H. (2015) Technical and Clinical Aspects of Cortisol as a Biochemical Marker of Chronic Stress. BMB Reports, 48, 209-216.

https://www.google.com/url?sa=t\&source=web\&cd=12\&ved=2ahUKEwiMk8zVlc_c AhXLHDQI-

HadMA6wQFjALegQIBhAB\&url=https\%3A\%2F\%2Fwww.ncbi.nlm.nih.gov\%2Fpm c\%2Farticles\%2FPMC4436856\%2F\&usg=AOvVaw0QGSdiKiEKkgE4PV_GCn2Z https://doi.org/10.5483/BMBRep.2015.48.4.275

[66] Wester, V.L. and van Rossum, E.F.C. (2015) Special Section View, Clinical Applications of Cortisol Measurements in Hair. European Journal of Endocrinology, 173, M1-M10. http://www.eje-online.org/content/173/4/M1.long https://doi.org/10.1530/EJE-15-0313

[67] Russell, E., Kirschbaum, C., Laudenslager, M., Stalder, T., de Rijke, Y., van Rossum, E.F.C., et al. (2015) Toward Standardization of Hair Cortisol Measurement: Results of the First International Interlaboratory Round Robin. Therapeutic Drug Monitoring, 37, 71-75.

https://journals.lww.com/drug-monitoring/Abstract/2015/02000/Toward_Standardi zation_of_Hair_Cortisol.10.aspx https://doi.org/10.1097/FTD.0000000000000148

[68] Gow, R., Thomson, S., Rieder, M., Van Uum, S. and Koren, G. (March 2010) An Assessment of Cortisol Analysis in Hair and Its Clinical Applications. Forensic Science International, 196, 32-37.

http://www.sciencedirect.com/science/article/pii/S0379073809005416 https://doi.org/10.1016/j.forsciint.2009.12.040

[69] Pereg, D., Chan, J., Russell, E., Berlin, T., Mosseri, M., Seabrook, J.A., Koren, G. and Van Uum, S.H. (2013) Cortisol and Testosterone in Hair as Biological Markers of Systolic Heart Failure. Psychoneuroendocrinology, 38, 2875-2882.

https://www.sciencedirect.com/science/article/pii/S0306453013002655 https://doi.org/10.1016/j.psyneuen.2013.07.015

[70] Grine, A. and Rackley, S. (nd) Presumptive and Confirmatory Forensic Tests. https://www.sog.unc.edu/sites/www.sog.unc.edu/files/course_materials/Presumptiv e\%20and\%20Confirmatory\%20Forensic\%20Tests.pdf

[71] FDA (Food and Drugs Administration December 28, 2016) Food and Drugs Ad- 
ministration Warns of False Positive Results with Zika Test. Results from ZIKV Detect Assay Require Confirmatory Testing. Managed Care Magazine.

https://www.managedcaremag.com/news/fda-warns-false-positive-results-zika-test

[72] CDC. Centers for Disease Control and Prevention Zika MAC-ELISA Updated: May 3, 2017). Fact Sheet for Healthcare Providers: Interpreting Zika MAC-ELISA Test Results. https://www.cdc.gov/zika/pdfs/interpreting-zika-mac-elisa-results.pdf

[73] Report and Independent Review (December 15, 2015) Report of the Motherisk Hair Analysis and Independent Review. The Honourable Justice Susan Lang, Independent Reviewer. https://www.attorneygeneral.jus.gov.on.ca/english/about/pubs/lang/

[74] Statement of Claim. Koskie Minsky LLP (January 20, 2015) Statement of Claim Issued in SickKids "Motherisk" Lab Class Action. Minsky LLP and Sutts, Strosberg LLP Have Issued a Statement of Claim.

https://kmlaw.ca/cases/motherisk-class-action/

[75] Slominski, R., Rovnaghi, C.R. and Anand, K.J.S. (2015) Methodological Considerations for Hair Cortisol Measurements in Children. Therapeutic Drug Monitoring, 37, 812-820.

https://journals.lww.com/drug-monitoring/Abstract/2015/12000/Methodological_C onsiderations_for_Hair_Cortisol.17.aspx

https://doi.org/10.1097/FTD.0000000000000209

[76] Krogh, C.M. and Aramini, J.J. (July 2017) Project Title: Investigating the Relationship between Noise and Other Exposures and Associated with Living within $10 \mathrm{~km}$ of an Industrial Wind Energy Facility, Status Update: Research Data Center (RDC). Wind Action. Status: Aramini-Krogh Project to Evaluate Health Canada Wind Turbine Noise and Health Study.

http://www.windaction.org/posts/47021-status-aramini-krogh-project-to-evaluatehealth-canada-wind-turbine-noise-and-health-study

[77] ATIP (2016) Access to Information and Privacy Request. Health Canada Wind Turbine Noise and Health Study, Request for Raw Data Elements.

[78] ATIP (2015) Access to Information and Privacy Request. Health Canada Wind Turbine Noise and Health Study, Request for Raw Data Elements.

[79] Barry, R., Sulsky, S.I. and Kreiger, N. (June 2018) Using Residential Proximity to Wind Turbines as an Alternative Exposure Measure to Investigate the Association between Wind Turbines and Human Health. The Journal of the Acoustical Society of America, 143, 3278-3282.

https://docs.wind-watch.org/Residential-proximity-wind-turbine-health-exposure.p df

https://doi.org/10.1121/1.5039840

[80] Federal Court of Canada (July 9, 2018) Mr. Justice Grammond. Dockets: T-335-17, T-336-17. Ottawa, Ontario, Canada. Citation: 2018 FC 710. Doshi v. Attorney General of Canada.

[81] Rideout, K., Copes, R. and Bos, C. (January 2010) Wind Turbines and Health. National Collaborating Centre for Environmental Health.

http://www.ncceh.ca/sites/default/files/Wind_Turbines_January_2010.pdf

[82] CMOH (May 2010) The Potential Health Impact of Wind Turbines. Chief Medical Officer of Health Report.

http://www.health.gov.on.ca/en/common/ministry/publications/reports/wind_turbi ne/wind_turbine.pdf

[83] Krogh, C. and Horner, B. (2017) Human Health, Rights and Wind Turbine Deployment in Canada. Open Journal of Social Sciences, 5, 166-185. 
https://file.scirp.org/pdf/JSS_2017051714591773.pdf https://doi.org/10.4236/jss.2017.55012

[84] Jarosińska, D., Héroux, M.-È., Wilkhu, P., Creswick, J., Verbeek, J., Wothge, J. and Paunović, E. (2018) Development of the WHO Environmental Noise Guidelines for the European Region: An Introduction. International Journal of Environmental Research and Public Health, 15, 813. https://doi.org/10.3390/ijerph15040813

[85] Poulsen, A.H., Raaschou-Nielsen, O., Peña, A., Hahmann, A.N., Nordsborg, R.B., Ketzel, M., Brandt, J. and Sørensen, M. (2018) Short-Term Nighttime Wind Turbine Noise and Cardiovascular Events: A Nationwide Case-Crossover Study from Denmark. Environment International, 114, 160-166.

https://www.sciencedirect.com/science/article/pii/S0160412017317889 https://doi.org/10.1016/j.envint.2018.02.030

[86] Kasprzak, C. (2014) The Influence of Infrasound Noise from Wind Turbines on EEG Signal Patterns in Humans. Acta Physica Polonica A, 125, A20-A23.

http://docs.wind-watch.org/Kasprzak-2014-infrasound-wind-turbines-EEG.pdf https://doi.org/10.12693/APhysPolA.125.A-20

[87] Weichenberger, M., Bauer, M., Kühler, R., Hensel, J., Forlim, C.G., Ihlenfeld, A., et al. (2017) Altered Cortical and Subcortical Connectivity Due to Infrasound Administered near the Hearing Threshold-Evidence from fMRI. PLoS ONE, 12, e0174420.

http://journals.plos.org/plosone/article?id=10.1371/journal.pone.0174420 https://doi.org/10.1371/journal.pone.0174420

[88] Cooper, S.E. and Chan, C. (2017) Subjective Perception of Wind Turbine Noise-The Stereo Approach. Proceedings of Meetings on Acoustics, Vol. 31, New Orleans, Louisiana. http://acousticalsociety.org/

[89] Fredianelli, L., Carpita, S. and Licitra, G. (2018) A Procedure for Deriving Wind Turbine Noise Limits by Taking into Account Annoyance. Science of the Total Environment, 648, 728-736.

https://www.sciencedirect.com/science/article/pii/S0048969718330717?via\%3Dihub https://doi.org/10.1016/j.scitotenv.2018.08.107

[90] WHO (2018) World Health Organization. Environmental Noise Guidelines for the European Region. Dr Zsuzsanna Jakab. WHO Regional Director for Europe. Regional Office for Europe.

http://www.euro.who.int/_data/assets/pdf_file/0008/383921/noise-guidelines-eng. pdf

[91] WCO. Wind Concerns Ontario (July 17, 2018) Ottawa Area Community Ramps up Wind Farm Fight.

https://ottawawindconcerns.com/tag/ontario-ministry-of-environment/

[92] North Stormont v. Ontario, Ministry of Environment and Climate Change (June 20, 2018) Case 18-028, Ontario Environmental Review Tribunal. Renewable Energy Approval Appeal. Nation Rise Wind Power Project. North Stormont, Ontario. Witness Statement by Wilson JE.

[93] GEA (Green Energy and Green Economy Act, 2009) S.O. 2009, c. 12-Bill 150, Ontario, Canada. An Act to Enact the Green Energy Act, 2009 and to Build a Green Economy, to Repeal the Energy Conservation Leadership Act, 2006 and the Energy Efficiency Act and to Amend Other Statutes. Schedule G, 48.

https://www.ola.org/sites/default/files/node-files/bill/document/pdf/2009/2009-05/b ill---text-39-1-en-b150ra.pdf

[94] BioInitiative Working Group. Sage, C. and Carpenter, D.O., Eds. (December 31, 2012) BioInitiative Report: A Rationale for Biologically-Based Public Exposure 
Standards for Electromagnetic Radiation. Appendix 20-B. Standards of Evidence for Decision making Differs among Professions Pg 7, 8 Appendix III for Levels of Proof Schema. http://www.bioinitiative.org/

[95] ATIP (2012) Access to Information and Privacy request. Health Canada. Innovation and Technology: Ensuring Health Benefits and Managing Risks for Canadians. Presentation by Paul Glover, Director General, Safe Environments Programme. AWMA Conference Calgary, September 16, 2005.

[96] ATIP (2012) Access to Information and Policy request. Health Canada Policy and Research Approach for Wind Turbine Noise. A Presentation to the Science Advisory Board. Policy.

[97] Berglund, B., Lindvall, T. and Schwela, D.H., Eds. (1999) Guidelines for Community Noise. Part 5. Noise Management. WHO, World Health Organization.

https://www.who.int/docstore/peh/noise/Comnoise-5.pdf

[98] McMurtry, R.Y. and Krogh, M.E. (2014) Diagnostic Criteria for Adverse Health Effects in the Environs of Wind Turbines. JRSM Open, 5.

http://shr.sagepub.com

http://www.ncbi.nlm.nih.gov/pubmed/?term=Diagnostic+criteria+for+adverse+hea lth+effects+in+the+environs+of+wind+turbines

https://doi.org/10.1177/2054270414554048

[99] Guideline of the Austrian Medical Association for the Diagnosis and Treatment of EMF-Related Health Problems and Illnesses (EMF Syndrome). Consensus Paper of the Austrian Medical Association's Working Group AG-EMF.

http://electromagnetichealth.org/wp-content/uploads/2012/04/EMF-Guideline.pdf 